\title{
Echocardiographic diagnosis of mobile left ventricular tumour
}

\author{
G. SABOT, J. M. FAUVEL, AND J. P. BOUNHOURE \\ From the Department of Cardiology, Rangueil Hospital, Toulouse, France
}

SUMMARY Echocardiography detected a mobile left ventricular tumour. The tracing showed a cluster of echoes in the left ventricular outflow tract corresponding to the location of the tumour as confirmed by cineangiograms. At operation, a thrombus was discovered, attached to a chorda tendineae.

Cardiac tumours are commonly found in the left atrium, and many reports have dealt with their ultrasonic detection in this region. Because left ventricular tumours are rare, their echocardiographic observation has been infrequent. In this report, we describe the echocardiographic features of a mobile left ventricular tumour.

\section{Case report}

This 28-year-old salesman was admitted to the Department of Cardiovascular Surgery of our hospital in January 1978, because of acute ischaemia of the right lower limb.

There was a history of an anterior myocardial infarction 5 years before admission; the coronary angiogram performed 2 months after recovery had shown a muscular bridge pattern affecting the left anterior descending coronary artery, with dyskinesia in the corresponding region of the ventricular wall. In October 1977, he suffered acute occlusion of the distal abdominal aorta necessitating thrombectomy. In November 1977, he was referred to another hospital for an acute occlusion of the right femoral artery, and embolectomy was successfully performed with a Fogarty catheter. Subsequent left heart angiography showed no filling defect; however, an operation was performed: no thrombus was found in the left ventricular cavity, but a fibrous scar was present, anteriorly located, and was partly excised. The patient recovered very well and was working until the last event.

Cardiac examination disclosed a normal apical impulse and normal first and second heart sounds; there was no gallop or murmur. The right femoral pulse was absent. The chest $x$-ray film was normal, and the electrocardiogram showed the signs of an anterior left ventricular aneurysm.
Embolectomy was again necessary, and echocardiography was performed the next day.

The recording showed a cluster of echoes in the left ventricular outflow tract, seen only during systole, between the closed mitral valve and the intraventricular septum as well as a normal left atrium, and normal mitral and aortic valve cusps (Fig. 1). These abnormal echoes were denser as the ultrasonic beam was directed more inferiorly (Fig. 2).

This finding prompted us to perform a cineangiographic study with a pulmonary arterial injection. It showed a fixed filling defect near the apex of the left ventricle, and a second mobile one was seen to move into the left ventricular outflow tract during systole and return towards the apex during systole.

With a presumptive diagnosis of left ventricular thrombus, the patient was submitted to open-heart surgery. Operation revealed 2 thrombi. A small one, the size of an olive, was attached to a chorda tendineae going from the anterior papillary muscle to the posterior one and transversely to the left ventricular cavity. The second one was larger, near the apex, with a stalk originating from a small area of remaining scar tissue around the first ventriculotomy. The 2 thrombi were removed and the fibrous tissue was completely excised. The postoperative course was uneventful and the echocardiogram was normal 4 months after operation.

Microscopical study showed a thrombus with early organisation.

\section{Discussion}

The usefulness of echocardiography in diagnosing atrial tumours was established 19 years ago by Effert and Domanig (1959). Several cases of left 


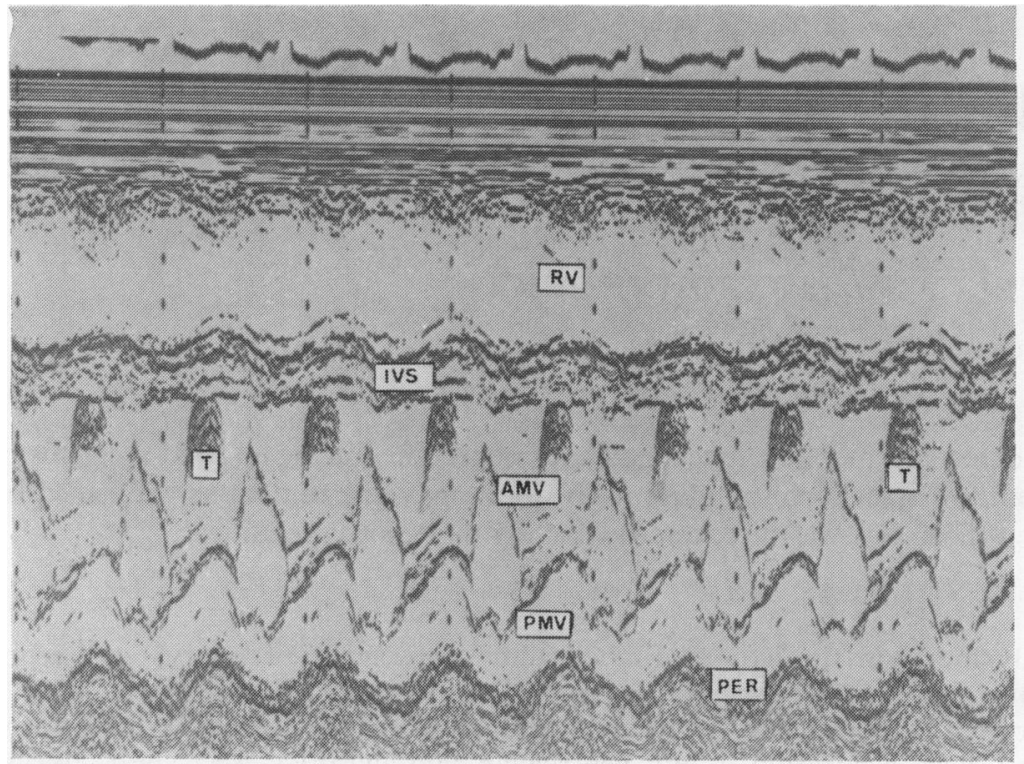

Fig. 1 The ultrasonic beam passes through the left ventricular chamber at the level of the edges of the mitral valve leaflets. The tumour is represented by a cluster of echoes in the left ventricular outflow tract during systole. (PER, pericardium; $A M V$, anterior mitral valve; $P M V$, posterior mitral valve; $T$, tumour; IVS, interventricular septum; $R V$, right ventricle.)

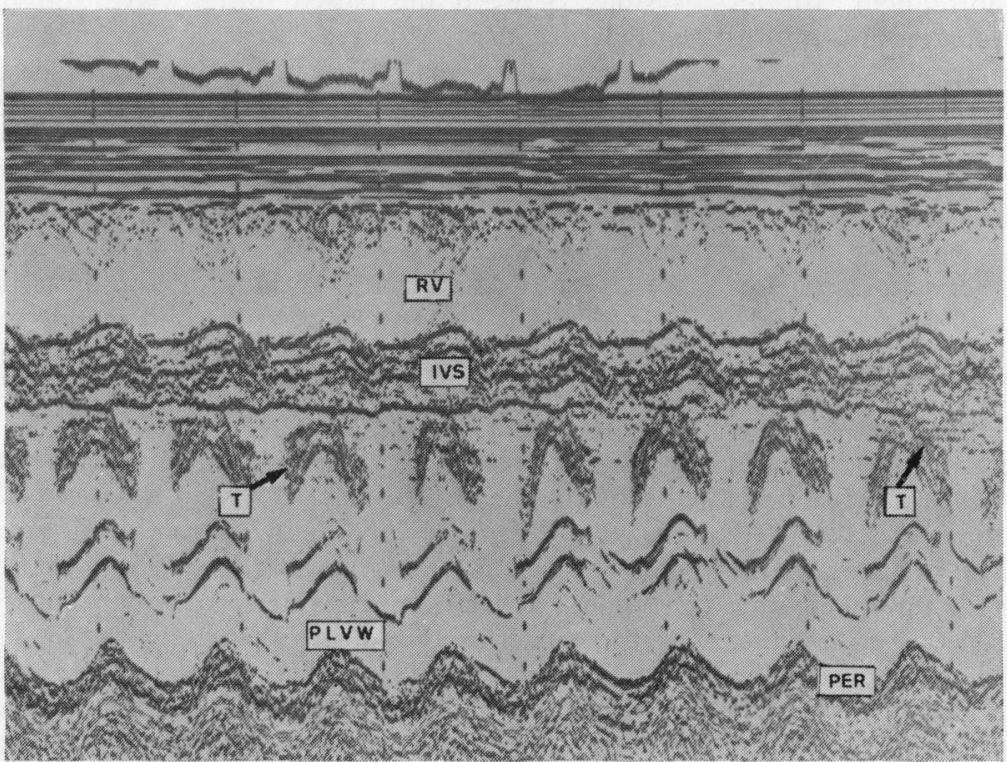

Fig. 2 The transducer is directed towards the apex; abnormal echoes are larger, and seen only during diastole. (PLVW, posterior left ventricular wall; other abbreviations as in Fig. 1.)

ventricular tumours diagnosed with echocardiography have been reported since 1974. Most of them were not mobile, and the echocardiographic pattern proved to be identical, whatever the tumour (rhabdomyoma, Farooki et al., 1974; idiopathic calcified myocardial mass, Patterson et al., 1974; alveolar rhabdomyosarcoma, Orsmond et al., 1976; myxoma, Morgan et al., 1977). The tracings showed a dense mass of echoes in the left ventricular chamber, anterior to the anterior mitral leaflet, and present in systole and diastole.
The tracing of our patient shows a cluster of echoes in the left ventricular outflow tract only during systole. A flail aortic valve would be visible in exactly this position, but only during diastole.

The first echocardiographic diagnosis of a mobile left ventricular tumour was reported in 1975 by Levisman et al. Their patient presented with multiple emboli to the brain, to the femoral artery, and to the lower peripheral arteries. The echocardiographic recording was similar to ours. Open heart surgery showed a pedunculated throm- 
bus.

To our knowledge, our case is the second one diagnosed by echocardiography, before angiography and operation.

In patients with an unexplained thromboembolic vascular accident, echocardiography should be a useful means of detecting left heart tumours.

We are indebted to Professor A. Enjalbert for allowing us to study this patient who was under his care in the Department of Cardiovascular Surgery of the Rangueil Hospital, to Dr H. Boccalon who performed the angiographic study, and to Dr A. Cerene who operated on this patient.

\section{References}

Effert, S., and Domanig, E. (1959). The diagnosis of intraatrial tumours and thrombi by ultrasonic echo method. German Medical Monthly, 6, 1-3; 17-18.
Farooki, Z. A., Henry, J. G., Arciniegas, E., and Green, E. W. (1974). Ultrasonic pattern of ventricular rhabdomyoma in two infants. American fournal of Cardiology, 34, 842-844.

Levisman, J. A., MacAlpin, R. N., Abbasi, A., Ellis, N., and Eber, L. M. (1975). Echocardiographic diagnosis of a mobile, pedunculated tumour in the left ventricular cavity. American fournal of Cardiology, 36, 957-959.

Morgan, D. L., Palazola, J., Reed, W., Bell, H. H., Kindred, L. H., and Beauchamp, G. D. (1977). Left heart myxomas. American fournal of Cardiology, 40, 611-614.

Orsmond, G. S., Knight, L., Dehner, L. P., Nicoloff, D. M., Nesbitt, M., and Bessinger, F. B., jun (1976). Alveolar rhabdomyosarcoma involving the heart. An echocardiographic, angiographic and pathologic study. Circulation, 54, 837-843.

Patterson, D., Gibson, D., Gomes, R., McDonald, L., Olsen, E., Parker, J., and Ross, D. (1974). Idiopathic calcified myocardial mass. Thorax, 29, 589-594.

Requests for reprints to Professor J. P. Bounhoure, Hôpital de Rangueil, 31054-Toulouse Cedex, France. 